Indexaciones: Repositorio de Revistas UCR, DIALNET, Latindex, REDALYC Directorio y recolector de recursos digitales del Ministerio de Cultura de España, Directory of Open Access Journals. Diálogos Revista Electrónica de Historia ISSN 1409-469X. Número especial 2008. Dirección web: http://historia.fcs.ucr.ac.cr/dialogos.htm

\section{"Causas y Consecuencias de la Emigración Internacional de Nicaragüenses en la Segunda Mitad del Siglo XX"}

MSc. Elena del Rosario Dávila Arriola

eledavila@hotmail.com

Universidad Nacional Autónoma de Nicaragua-Managua Recinto Universitario "Rubén Darío"

Facultad de Humanidades y Ciencias Jurídicas

Departamento de Historia. 


\section{CAUSAS DE LA EMIGRACIÓN DE LOS NICARAGÜENSES}

\section{Económicas:}

\subsection{Situación económica de Nicaragua}

Durante el gobierno revolucionario entre 1987 y 1988, y en la década de los noventa, las políticas económicas y sociales tenían como meta resolver el déficit público y comercial respectivamente, esto requiere disminuir gastos y aumentar ingresos. En ese ámbito se dan las medidas privatizadoras, la expulsión del empleo del sector público, la disminución del gasto público. Facilitaron el funcionamiento del mercado, que permite el crecimiento y su impacto en la reducción de la pobreza. Pero los beneficios del mercado no evitaron que el $45 \%$ de la población sobreviva con menos de 1 dólar diario y casi el $70 \%$ lo haga con menos de 2 dólares, esto demuestra el estado deplorable de pobreza al que han sido sometidas muchas de las familias en Nicaragua.

De los logros macroeconómicos, los más destacados fueron la estabilidad de precios y la relativa estabilidad del tipo de cambio. El mayor fracaso es el déficit en cuenta corriente en la balanza de pagos. Otra característica ha sido la corrupción. Y es en este contexto que se ha desarrollado un éxodo masivo de nicaragüenses al exterior. El poder adquisitivo de los trabajadores nicaragüenses evidencia deterioro. El costo de la canasta básica ha superado el salario promedio real, y esto afecta a las familias en el país. En 1992 se podía adquirir con un salario real más de 1,5 de la canasta básica y en el 2002 solamente se adquiere el 70\% de la misma. ${ }^{1}$

Existe desigualdad en la distribución del ingreso entre las familias, el 20\% de las familias con menos ingresos solamente recibe el 3,6\% mientras otro $20 \%$ que poseen mayores ingresos se apropian del $62,4 \%$ del ingreso total', esto impide en el mercado laboral la generación de empleo. Especialmente sufre el sector agrícola donde los principales problemas son la tenencia de la tierra, leyes, incentivos y regulaciones desactualizadas. Y por otro lado el Estado, con una inversión social baja, más bien estimula la migración.

\subsection{Búsqueda de empleo}

El proceso de privatización contribuyó a la expulsión del empleo público. En 1997 en Nicaragua

1 Red Nicaragüense de la Sociedad Civil para las migraciones. Cuaderno Migratorio No.8 Emigraciones Internacionales de Nicaragüenses. Nicaragua, 2006. p.15

2 Red Nicaragüense...Op. Cit. Pág. 18 
por cada 5,8 habitantes trabajaba una persona, recibe sus ingresos sin las preocupaciones del desempleo, lo que viene a ser una de las razones principales de las migraciones, así como la falta de oportunidades para la inserción de la población en actividades productivas y remunerativas.

Influyen también en las migraciones al exterior, las condiciones y atractivo del país de acogida, como el caso de Costa Rica que ha tenido en sus últimas décadas tasas de desempleo inferiores a las de Nicaragua y otros países de América Latina. El mercado laboral permite que los nicaragüenses elijan este país ante la falta de empleo en Nicaragua. Además los salarios en Nicaragua, están muy por debajo de los de Costa Rica, en diferentes actividades.

El país de origen soluciona la demanda de trabajo, el de destino su mano de obra para trabajar. Desde la década de los ochenta la fuerza de trabajo nicaragüense resulta clave en la reinserción de Costa Rica en la economía internacional. Las empleadas domésticas nicaragüenses facilitan la inserción de la mujer costarricense al mercado laboral, industrial o de servicio. Las principales causas $^{3}$ de la emigración nicaragüense son las condiciones materiales de vida, la pobreza, la ausencia de una estrategia de desarrollo. Se vuelve una respuesta frente a la corrupción, a la falta de acciones del Estado frente a las hambrunas, a la inequidad visible en los mega salarios, frente a los salarios bajos de la mayoría de los empleados.

La nueva migración propugna el interés de los hogares de enviar al exterior algún miembro de la familia para garantizarse el crédito, los seguros y el subsidio, evitando así restricciones y eliminando riesgos, es una manera de tener estabilidad y seguridad de la economía familiar. El escaso desarrollo educativo del nicaragüense ratifica la teoría de los mercados duales, según el cual el migrante se sitúa en un segmento del mercado de trabajo que ha sido dejado por el nacional siendo ocupado por el inmigrante. Si es femenino se emplea principalmente en tareas de servicio doméstico, si es masculino en la producción industrial poco especializada, y en el sector informal para ambos sexos.

En el caso de los hombres nicaragüenses, la participación laboral está concentrada en la agricultura, la industria, la construcción, el comercio y los servicios. Las mujeres se concentran en servicios domésticos, actividades de limpieza en el sector turístico y finalmente en la industria. Entre 1989y 1991 contaba con aproximadamente 150.000 nicaragüenses y a mediados de la década de los noventa contó con 250.000 inmigrantes indocumentados y posteriormente se habló entre

$3 \quad$ Red de Migraciones. Op. Cit. P.17 
350 y 500 mil ciudadanos de origen nicaragüense. Según Oscar René Vargas, cita economista e historiador nicaragüense, la pobreza aguda y el desempleo fueron los principales elementos que incidieron en los movimientos de nicaragüenses en calidad emigrantes especialmente hacia Costa Rica. Las causas no son los conflictos bélicos, sino producto de las condiciones internas deterioradas en Nicaragua. En 1998 existía un 53\% de la población nicaragüense económicamente activa.

Las principales causas de la emigración nicaragüense durante en los últimos cincuenta años, estriban en la falta de generación de empleos e inversión de capital en el país. Mientras se de esta situación, se van a seguirse desarrollando las corrientes migratorias, aunque irónicamente los mismos nicaragüenses, sienten que hay muchos conciudadanos en esos lugares. El motor de migraciones afecta edades económicamente activas; se vincula al desempleo, se va un miembro de la familia, el jefe de la familia o una pareja o la familia. También hay personas que tienen trabajo pero quieren mejorar. Aunque los independientes son más bien en términos teóricos, falta la seguridad social, tanto para jóvenes, como para mayores. Especialmente por razones económicas, evasión de servicio militar o estudiar o vivir mejor en otros países

Por lo general la emigración es laboral, en 1988 no hay registros significativos, se acogen como refugiados políticos para resolver problemas económicos. Del 2005 al 2007 existe una emigración técnica, no solamente a Estados Unidos, sino también a España y Canadá. Otros por deseos de vivir en otros lugares, por reencuentro familiar, por casarse. Según los entrevistados las principales décadas en que ha habido migración de nicaragüenses, son en los años noventa y dos mil, pero consideran que la migración de los nicaragüenses es desde los años setenta. Se cruzaban los muchachos para evitar conflictos de guerra de guerrillas que se daban en el país desde esa década y después los siguió. Mucha gente también ha regresado al país.

Entre las principales causas de la emigración de los nicaragüenses, mencionaron que en la década de los ochenta lo hicieron por los problemas económicos del país, por la existencia de las tarjetas de racionamiento, que limitaban la compra de alimentos y productos básicos del hogar. Era una situación de guerra y se sufría en el país un embargo económico internacional. Por el proceso de inflación diaria, pero ésta última continuó en menor medida en las dos últimas décadas. Se sumaron los niveles de desempleo. Otros por la política de gobierno de los sandinistas. Por razones económicas, cuando subió Alemán al poder. Buscaron por eso nuevas formas de vida, 
no había trabajo. "Por escasez de trabajo, necesidad de hambre, éramos familia numerosa y necesitamos progresar un poco más".

\section{Políticas:}

\subsection{El exilio de los años setenta y ochenta}

Los conflictos armados en los años setenta, en el área regional centroamericana y especialmente en Nicaragua, provocaron que miles de nicaragüenses se refugiaran en Estados Unidos y Costa Rica por la guerra y la política inestable en su tierra natal, ahora se enfrentan a la posibilidad de la deportación. Consideran que aún en los años noventa hay condiciones difíciles en Nicaragua.

Durante los años ochenta muchos nicaragüenses buscaron entre otros destinos el de Miami, especialmente para evadir el Servicio Militar. Después que el Gobierno Sandinista perdió el poder en 1990, había 75.000 nicaragüenses registrados que permanecían en Estados Unidos. El Congreso les garantizó el derecho de permanencia y otros eventualmente se convirtieron en ciudadanos americanos.

Los exilados nicaragüenses trabajaban con los cubanos en lugares como Hialeah y el East Little Havan de Miami. Llegaron a tener una relación de dependencia sobre todo por el idioma y por las similitudes en las condiciones políticas que los llevó a establecerse en ese lugar. Los censos pueden arrojar un nivel más alto de confianza. Aunque se puede tener problemas en una acertada información sobre la población nacida en el extranjero y sin manejar los países donde estos se encuentran. Los Estados Unidos admitieron entre 1989 y 1993 un total de 55.000 nicaragüenses, aunque las cifras estimadas por INEC alcanzaban las 350 mil personas.

En el Boletín Demográfico 54 del CELADE (1994) se muestran tasas de migración negativas en los años 1950, 1970 y 1980 y a partir del quinquenio 1990-1995 el saldo se hace positivo (3,72 por mil), se nota el aumento de la emigración de nicaragüenses en las décadas 1980 y 1990. Especialmente a partir de 1983, año en que se agudiza el conflicto bélico y los jóvenes se ven obligados a prestar el servicio militar. Es el contexto y determinantes posibles de la migración de nicaragüenses en los años 80 .

El proceso revolucionario, al reemplazar la presencia e iniciativa del sector privado, conduce a una pérdida de la capacidad empresarial del nicaragüense. Un síntoma categórico fue la 
fuga de capitales y el continuo déficit en la balanza de pagos. ${ }^{4}$

El valor de las exportaciones cayó en un 40\% y se incrementó la deuda externa. La inflación alcanzó un nivel de 3.343 en 1985 y de 3.300\% en 1984 y 13.500 en 1990.

\subsection{Migración forzada}

El refugio y el desplazamiento fueron algunas expresiones de la guerra en América Central, en la década de los años ochenta. Ello afectó a las relaciones sociales. Ambos aspectos constituyeron una expresión de migración por violencia, situación que no es exclusiva solamente de los pueblos centroamericanos, sino de otros territorios de América Latina. ${ }^{5}$ En el contexto de la crisis más de dos millones de centroamericanos abandonaron sus lugares y países de origen, especialmente para salvar sus vidas y la libertad, se considera una migración masiva producto de la violencia. Se identifica al refugiado cuando se dirige a otro país, que puede ser reconocido por el Estado del país receptor o bien no identificado. Por otro lado están los desplazados que se dirigen a otra parte del territorio del mismo país.

En cuanto al programa Consultas Mundiales sobre la Protección Internacional, si bien no es un documento jurídico, tiene un peso político y aunque no cubre todos los problemas de protección, se centra en aquellos que más se benefician producto de los compromisos y cooperaciones multilaterales. Comprende dos secciones: La Declaración de los Estados Partes y el Programa de Acción. Bajo la Convención de 1951 y los Estatutos de Refugiados y Protocolo de 1967.

Los objetivos del mismo están vinculados a seis metas entre sí: 1 . fortalecimiento de la Convención de 1951 y su Protocolo de 1967; 2. protección de los refugiados en los grandes movimientos migratorios; 3. distribución más equitativa de las cargas y responsabilidades y creación de capacidad para recibir y proteger a los refugiados; 4. tratamiento más eficaz de los problemas relacionados con la seguridad; 5 . intensificación de la búsqueda de soluciones duraderas para los refugiados; y 6. atención de necesidades de protección de las mujeres y los niños refugiados.

4 García Urbina Alma L. Naciones Unidas Nicaragua: País de Emigrantes? Beca Rafael Salas, Chile, 1977. p. 18

$5 \quad$ IIDH. Instituto Interamericano de Derechos Humanos. Éxodos en América Latina. la migración por violencia en Centroamérica. 1980-1990. 7. Área de promoción y asistencia ONG. Programa para refugiados, repatriados y desplazados. Costa Rica, 1992. Pág.3-17 
El tratamiento más eficaz de los problemas relacionados con la seguridad que afrontan los refugiados, debido a las separaciones de las familias, la impunidad de los criminales contra emigrantes, especialmente las mujeres y niños que son más vulnerables, incluso a diferentes formas de abusos, como violación, secuestro y trata y los jóvenes adolescente son objetos de reclutamiento forzoso. En este particular, se sugiere a los Estados garantizar acceso a la enseñanza y la formación profesional a estos adolescentes y así prevenir el reclutamiento militar. Y por otro lado elaborar programas para desarmar, desmovilizar y reintegrar a los niños soldados.

Otras convenciones importantes son la Convención de 1969 de la Organización de la Unidad Africana (OUA), la Declaración de Cartagena, Colombia de 1984, las Conclusiones del Consejo Europeo de 1999 en Tampere. En general debe brindarse protección a los refugiados, incluyendo la naturaleza de los conflictos armados, las continuas violaciones de los derechos humanos y del derecho internacional humanitario, los actuales patrones del desplazamiento, los flujos mixtos de poblaciones, los altos costos de albergar un gran número de refugiados y solicitantes de asilo y de mantener los sistemas de asilo, el crecimiento de tráfico y contrabando de personas, las dificultades para evitar el abuso de los sistemas de asilo y para excluir y repatriar a aquellos que no tienen derecho o no requieren protección internacional, así como la situación de refugiados de larga duración.

El programa de acción busca seis metas: Fortalecimiento de la aplicación de la Convención de 1951 y del Protocolo de 1967;Protección de los refugiados en los grandes movimientos migratorios; Distribución más equitativa de las cargas y responsabilidades y creación de capacidad y proteger a los refugiados; Tratamiento más eficaz de los problemas relacionados con la seguridad; Intensificación de la búsqueda de soluciones duraderas; y atención de las necesidades de protección de las mujeres y los niños refugiados.

\section{Sociales y culturales:}

Especialmente están relacionadas con la escolarización de los emigrantes nicaragüenses, ${ }^{6}$ de 15 años y más de edad tienen un promedio de 5,4 años de estudio, un 16,1\% ningún grado de educación formal, un 26,2\% cuentan con estudios de la primaria completa, un 11,1\% la secundaria completa o más. En general poseen un bajo nivel de escolaridad.

6 Encuesta de Hogares, Costa Rica, 2000. 


\section{CONSECUENCIAS DE LA EMIGRACIÓN DE NICARAGÜENSES}

\section{Económicas.}

\subsection{Papel de las remesas}

El Estado por su lado debe crear políticas migratorias que faciliten las transferencias de las remesas, con la reducción de las tarifas de las instituciones que transfieren el dinero, como las tasas y los impuestos adicionales impuestos por el cambio de moneda. Este dinero viene destinado a los más pobres y es importante asegurar la llegada del máximo de este dinero y de forma segura a sus receptores y que las remesas no sustituyan los esfuerzos públicos o de la política de cooperación internacional ${ }^{7}$.

Las remesas se constituyen como un salario regular para las familias con algún miembro en el exterior. Funcionan cuando en el país no quedan alternativas de obtener dinero a través de un empleo u otras actividades de sector informal. A su vez son un efecto importante para la población nicaragüense. Por lo general se destinan para la subsistencia, divididos entre la alimentación, la salud, la educación, mejoras del patrimonio familiar y una mínima parte para ahorro y el ocio. Pero requieren de un mejor uso en cuanto su productividad, puesto que las mismas no pueden ser siempre el principal sustento económico de las familias receptoras ${ }^{8}$.Los migrantes buscan un empleo y dejan familias en Nicaragua con la convicción de trabajar para ayudar a sus familiares a través de remesas, que cubren los principales gastos de subsistencia. El dinero enviado por los emigrantes nicaragüenses en Estados Unidos, se ha convertido en indispensable recurso, puesto que Nicaragua tiene una frágil economía y no se han creado políticas de retorno de los refugiados que podrían regresar.

Aproximadamente el 20\% de los hogares nicaragüenses reciben remesas del exterior que viene a ser otro ingreso en la economía nicaragüense, especialmente en los hogares urbanos, la

$7 \quad$ Entre 1998 y el 2001, el 48\% de los hogares con miembros residiendo en el exterior, han disminuido su estatus de pobre. Uno de cada cinco hogares recibe alguna remesa. Nicaragua recibe cerca de 800 millones de dólares al año en remesas, representando alrededor del 15\% del PIB. Estas son significativas, así la migración internacional se constituye en un fenómeno importante para el desarrollo económico y social del país.

8 En Nicaragua, las remesas tienen un impacto macroeconómico y socioeconómico, representan el 20\% del PIB, el 70\% del déficit comercial, el 140\% de las exportaciones FOB del país y superior en un $70 \%$ al monto de la cooperación internacional. 
mayor parte de ellas son especialmente de dinero o combinado con bienes o regalos. Los montos andan entre los 600 y 1.200 dólares anuales, esto es lo que expresan las personas en las que se ha hecho estudios de encuestas de hogares por parte del Instituto de Estadísticas y Censos, en el 2001. Similares costes tienen los bienes o regalos recibidos. Por lo general las remesas son recibidas mensualmente, aunque hay otros que las reciben trimestral o anualmente. Pueden recibir de uno o dos miembros de la familia que se encuentra en el exterior.

De hecho, la estructura de los hogares con migrantes ha mitigado la pobreza, en relación con aquellos que no los tienen. Aunque es importante señalar que esto también tiene que ver con las condiciones de vida previas que tenían estos hogares. Un aspecto negativo de las remesas sobre los hogares es que crean dependencia de las mismas y no los motiva a trabajar. Por otro lado, el hecho que los familiares hayan partido, sobre todo cuando se refiere a la madre o el padre que según los estudios se acercan al 55\%, esto ocasiona problemas emocionales y de orientación en los hijos que quedan con otros familiares o amistades. Según informes de CEPAL en relación al uso productivo de las remesas en Centroamérica, en Nicaragua, las mismas han venido creciendo y en algunos casos constituyen fuentes únicas de solución para el consumo de las familias, pago de deudas o pequeñas inversiones

Existen diversos informes de la situación económica de Nicaragua que empuja a muchos nicaragüenses al fenómeno de la migración, el Informe sobre Desarrollo Humano de las Naciones Unidas de 1998 ubicó a Nicaragua en el lugar 126, el Banco Central de Nicaragua refiere que el desempleo es de $13,2 \%$, otras instituciones discrepan por considerar como parte del mismo el subempleo. El FIDEG calcula que el $40 \%$ de los hogares tienen familiares en el exterior. Calcular el flujo de remesas es un poco complicado por la falta de registro o sistema de información, se ha conocido que las remesas ingresan por las Agencias con cobros de comisiones tanto en el país de origen como el destino de las mismas.

Nicaragua se encuentra entre los cuatro primeros países de América Latina que reciben remesas de acuerdo con el Producto Interno Bruto (PIB) del país, al tiempo que ocupa también un quinto lugar en migraciones, según su población, estima un estudio realizado por el Banco Mundial. El estudio sostiene que Nicaragua ocupa el cuarto puesto en recepción de remesas, relacionándolo con la densidad poblacional del país. En ese sentido, alrededor de un 16\% de las familias nicaragüenses reciben estas remesas, sostiene el economista Humberto López, de 
la Oficina de América Latina del Banco Mundial. Extraoficialmente se ha dicho que Nicaragua podría estar recibiendo anualmente alrededor de 800 millones de dólares ${ }^{9}$.

\subsection{Efectos económicos de la migración sobre las sociedades de origen y destino.}

Los inmigrantes en Estados Unidos son necesitados por las compañías americanas, aprovechando las diversas habilidades de los mismos. Los trabajos que requieren poca educación son desarrollados por los trabajadores extranjeros con un salario menor que el que lo haría un nacional. Además demandan productos y atraen más capital y permiten la posibilidad del trabajo femenino fuera de casa.

Los estudiantes del país permanecen en las escuelas, por la competencia de los inmigrantes, los induce a estudiar para hacer labores más calificadas de las que hacen los inmigrantes. En Estados Unidos los críticos del papel de los inmigrantes analizan su impacto en la economía del país. Algunos argumentan que podrían impedir el crecimiento económico y que los trabajadores extranjeros reducen las oportunidades de los ciudadanos del país, que ellos compiten por el trabajo. Sin embargo, estos argumentos, son discutidos por otros que valoran el trabajo de los inmigrantes en la economía a través del modelo dinámico, donde hay que reemplazar a los trabajadores que cambian de ocupación o se retiran.

En cuanto a la incidencia de las migraciones nicaragüenses en la vida económica del país de origen y los de destino, el $20 \%$ de los hogares nicaragüenses reciben remesas, con esto ayudan a sobrevivir, a prosperar a miles de personas.

Según los entrevistados, en relación con los salarios no satisfacen las de los migrantes pero al menos pagan los alquileres de casas, aunque éstas tienen pocas condiciones, les queda algo para comer, algunos pagan seguro para ser atendidos en los centros asistenciales de salud y una pequeña parte es destinada para enviarlos a sus familiares en Nicaragua. Aunque existe una parte que no envía del todo. Algunos trabajan por temporadas, trabajan en eventos. Una joven madre de familia expresó que quedó afectada físicamente después de un accidente en Nicaragua y lamentablemente por esa razón no le dieron trabajo en su país, así que decidió venir a Costa Rica y parte de su salario como doméstica lo envía a su hija. Algunos consideran que hay

$9 \quad$ El Nuevo Diario. Hemos expulsado a un quinto de la población del país. Nicaragua, cuarto país receptor de remesas en América Latina. Managua, Nicaragua, Viernes 22 de Junio, 2007. Edición 9646. 
salarios buenos y malos, que es cosa de suerte, pero realmente esto está vinculado con su estatus migratorio y su nivel educativo.

\section{Sociales, Políticas y Culturales.}

\subsection{Situación Familiar}

La fecundidad de Costa Rica tiene una tendencia decreciente, el comportamiento demográfico de los nicaragüenses y de mantenerse este comportamiento demográfico la población migrante nicaragüense en los próximos años contribuirá al sostenimiento de la estructura demográfica del país. En aspectos de atención a la salud, las edades de los que llegan de Nicaragua a Costa Rica oscilan entre 19 y 40 años; no tienen por tanto un gran consumo en los servicios de salud. Cuando son subcontratados o trabajan por su cuenta en las diferentes labores de la agricultura, construcción, servicios o comercios entre otros, en esas condiciones existe una baja cobertura del seguro.

Por otro lado el Ministerio de Salud de Costa Rica, la Organización Panamericana de la Salud (OPS) y FLACSO han planteado que han existido dificultades para generar información sobre las demandas específicas en salud, lo mismo que sus costos económicos. Aunque se reconoce que sus condiciones de salud están en correspondencia con sus condiciones de vida y trabajo: en un medio insalubre, viviendas inadecuadas, precariedad, con hacinamiento, inseguridad, deficiente situación de servicios básicos; en los trabajos expuestos con maquinarias incorrectas, con agroquímicos y pesticidas, jornadas prolongadas y desconocimiento de acciones preventivas. ${ }^{10}$

En cuanto a la vivienda en Costa Rica, la población ha aumentado en este país en los últimos cincuenta años y hoy en día se cuenta con un importante contingente de población migrante, principalmente nicaragüense. Estos habitan en lugares marginados en situación de precarios, con dificultades de acceso a una vivienda digna, adecuada. Esto ya se ha dicho varias veces A su vez tienen problemas de servicios sanitarios y agua, esto se asocia a las condiciones de salud. Según los estudios de Gática, un 2\% de los nicaragüenses en Costa Rica tienen viviendas totalmente pagadas, la otra parte están pagando a plazos, o es alquilada; viven en situación precaria. El 55\% de las viviendas en malas condiciones son habitadas por nicaragüenses, el $40 \%$ en muy mal estado, 15\% mala y 27,7\% Los fenómenos migratorios implican una serie de eventos

10 Gática, Gustavo Adolfo. "Las políticas de salud en el contexto de la demanda de la población migrante nicaragüense en Costa Rica.” En Migración y Políticas Públicas para el desarrollo. Costa Rica, 2007. Pág. 61 
traumáticos, tanto para los individuos que migran, como para la familia, grupos sociales y para las propias sociedades involucradas.

En términos sociales la presencia de irregulares genera para el país receptor una mayor demanda de servicios de salud, educación y vivienda. Para atender necesidades alimentarias, de salud y educación son atendidos por la asistencia social, redes de reciprocidad y créditos en las pulperías. En la entrevista con Rosaura Venegas expresó en primer lugar lo que ella junto con la iglesia hace por esta comunidad de La Carpio, tanto en la alimentación de los niños, como en aspectos de salud de los adultos. Ella trabaja con el Padre José Ernesto Ibarra de la Parroquia Santa Catalina de Alejandría, de la cual forma parte la Comunidad de La Carpio, formada por nicaragüenses y costarricenses, pero especialmente de los primeros, los cuales han puesto su sello distintivo de la cultura nicaragüense.

Las entrevistadas de La Carpio manifestaron que viven en su entorno con mucha inseguridad, debido a la presencia de delincuentes, temen por sus hijos y sienten que en este particular es un lugar sin ley, específicamente señalaron la cuarta parada frente a un lugar denominado Pavas, muy cerca del río. En otro lugar de la misma localidad se encuentra "La Cueva", donde se concentra la delincuencia, formado por muchachos que, a juicio de las entrevistadas, no tienen futuro. La Carpio es una zona insegura que, como a otros barrios marginados, le hacen falta centros recreativos deportivos para los jóvenes que se dedican a las situaciones antes señaladas. Una persona manifestó que este lugar se hizo a la "brava". De hecho, forma parte de los inmigrantes nicaragüenses que se han asentado en este lugar sin ningún título de propiedad, pero que son objetos de inquilinatos, por otro lado no solamente está formado por nicaragüenses, en este lugar convergen con los migrantes costarricenses que vienen de las zonas rurales o urbanas de fuera de la capital.

Según los entrevistados, en cuanto a los aspectos culturales y sociales explicaron que cada una de las culturas se ha integrado. Han venido adquiriendo valores del país en relación a su cultura por ejemplo la música, la danza, los hábitos de disciplina y aseo, pero sin olvidar sus propios aspectos culturales. Se ha aprendido a compartir con los vecinos. Otro elemento que les parece bien es cómo en este país se cumple con las leyes en relación a la obligación de la responsabilidad paterna, sienten que en Nicaragua no sucede igual. Han aprendido a ser, a tener identidad como nicaragüenses, a asistir a eventos culturales. Han aprendido un poco de 
educación y cómo llamarle la atención a sus hijos, "en Nicaragua se maltratan, aquí los tratan con amor”. Lo expresaron a partir de la experiencia de su niñez, esto lo señalaron especialmente las mujeres. En la forma de hablar insistieron que el acento es el de su país de origen, pero tienen que utilizar ciertos vocablos para establecer una mejor comunicación dentro de la localidad en que se encuentran. Por ejemplo las expresiones de "paño" en vez de "mechas de lampazo", que son los limpiadores de pisos, o por ejemplo "chupón" en vez de "pacha" que es el biberón de los niños. También han aprendido a cocinar comida costarricense.

En las comidas, se han metido la cocina costarricense, que les gusta mucho la comida nicaragüense, sobre todo el "baho" que es carne al vapor con verduras y acompañado con ensalada. Otro plato que les gusta es el "gallo pinto" (combinación de arroz con frijoles). Consideran que los nicaragüenses son más expresivos en dar a conocer su cultura y por eso es más fácil que se difunda entre los costarricenses.

De parte de los costarricenses reciben apoyo de la Iglesia Santa Catalina de Alejandría y de la Pastoral Social. Trabajan conjuntamente con esta institución eclesiástica que les facilita la integración a sus nuevas formas de vida, ayudándoles a que sea digna y con valores religiosos. Los apoyan en diferentes esferas de la vida social sobre todo en la salud, educación y alimentación para los niños. En relación a situaciones negativas observan que hay muchos focos de drogas y prostitución de las niñas, que en Nicaragua no se desarrollan en esas dimensiones.

\subsection{Situaciones de xenofobia}

Parte de la población costarricense consideran a la migración nicaragüense como una amenaza, un problema social, amenaza para su estabilidad democrática, consideran una invasión de nicaragüenses. Estiman que éstos son aproximadamente un millón, pero estas cifras se manejan según los medios y popularmente. Dicen que los nicaragüenses son violentos, que le quitan el empleo a los costarricenses, esto también según cifras no es cierto, otras afirmaciones como que los nicaragüenses van a hacer que colapse el estado de "bienestar tico", con expresiones como "son una plaga", "traen enfermedades", "aumentan pobrezas".

En una reciente encuesta del Centro Centroamericano de Población, en Costa Rica, en las respuestas en relación con la intolerancia, un 19\% manifestó actitudes muy desfavorables, 20\% algo desfavorable, un 19\% actitudes muy positivas y el 13\% algo positivas. En cuanto al grado 
de interacción, el 79\% tiene relaciones de amistad, el 59\% de vecindad.

En Estados Unidos la derecha mantiene que los latinoamericanos tienen una lealtad dividida entre Estados Unidos y su país de origen y que sus intereses han llegado a dominar la política exterior de Estados Unidos en detrimento de ese país. Uno de estos artículos fue expresado por el profesor de Harvard, Samuel Huntington de corriente conservadora en 1997. Este fue titulado "La erosión de los intereses nacionales" en la revista Foreign Affaire.

En Puebla, México, el 17 de febrero del año 2005, en el marco del foro "El Quijote desde América" James Iffland se refirió a la teoría de Samuel Huntington quien manifiesta que el auge de la cultura hispana en EE.UU es una “amenaza” para ese país, opinó que el experto estadounidense Huntington "no es un intelectual cualquiera, sino el ideólogo del sistema en Estados Unidos, por lo que sus planteamientos sobre los hispanos pueden resultar potencialmente peligrosos para México", dijo Iffland a la prensa. Añadió que el "influyente" profesor de Harvard planteó en un libro publicado en la década pasada que, después de la caída de la Unión Soviética, EE.UU debería enfrentar "la amenaza del mundo islámico, y ya vimos como se invadió a países como Afganistán e Irak”.

"Si el cerebro del poder en Estados Unidos está difundiendo ahora la idea en el imaginario colectivo de que los mexicanos son los enemigos, que quieren 'reconquistar'territorios perdidos en el siglo XIX ¿qué se podría esperar?”, se preguntó Iffland, profesor de literatura española de la Universidad de Boston ${ }^{11}$.

El trabajo de los inmigrantes es necesario, sin embargo, a veces, no es reconocido por razones de prejuicio y por la xenofobia existente hacia los migrantes nicaragüenses, que son culpados por los costarricenses de las epidemias, la criminalidad y el desempleo de nacionales, si bien es cierto, en los diferentes estudios realizados, se ha demostrado lo contrario, que contribuyen más bien a la economía de ese país y que son personas que buscan mejores condiciones de vida. Algunos medios de comunicación y autoridades gubernamentales contribuyen a profundizar los prejuicios en contra de la población migrante.

Según estudios de Carlos Sandoval en “Otros amenazantes” existe reacción de los costarricenses hacia los nicaragüenses, son los mitos, esto se manifiesta por las informaciones falsas sobre los grupos migrantes, hay identidades. Supuestamente se critica la forma de hablar, omisión de la 11 www.esmas.com/noticieros televisa/México. 17 de febrero, 2005. 
s, los modales, el uso del vos, poca utilización del diminutivo, el bajo nivel cultural, el aspecto físico. Estos son algunos indicadores formales que expresan la xenofobia.

Las expresiones xenofóbicas son más bien reacciones hacia los extranjeros, no es generalizado, pero en ocasiones se han manifestado situaciones grotescas o refinadas en competencia por el empleo, comentarios, chistes, es falso hacer creer que con los nicaragüenses la criminalidad ha aumentado, solamente hay el $5 \%$ de los prisioneros que son de Nicaragua, considera que los medios magnifican los acontecimientos, tanto en los medios de Nicaragua y Costa Rica, resaltando por los últimos que "es importante hacer algo para que no se vengan". Recordó de nuevo el caso Canda ${ }^{12}$, el cual repudió.

\subsection{Asociaciones de Identidad y Sociabilidad. Migración en Cadena y Retorno.}

Las redes migratorias facilitan la movilización de los nuevos migrantes que son apoyados por sus compatriotas, quienes ayudan en la incursión del mercado laboral. Las redes hacen de la migración un fenómeno perpetuado, cada desplazamiento es un recurso para quienes quedan atrás y facilitar desplazamientos ulteriores, que a su vez amplían las redes. Pueden definirse como conjuntos de relaciones interpersonales que vinculan los inmigrantes a emigrantes retornados 0 a candidatos a la emigración con parientes, amigos o compatriotas, ya sea en el país de origen o en el de destino. El desarrollo de las mismas puede explicar que la inmigración continúe, con independencia de las causas que llevaron al desplazamiento inicial, por lo que son, con frecuencia, los mejores predictores de flujos futuros.

Tienen familiares en Nicaragua y mantienen comunicación con los mismos sobre todo por teléfono. Les envían dinero pero no en grandes cantidades, otros no envían nada. En cuanto a la frecuencia con que van a Nicaragua, expresaron algunos que por lo general viajan una vez al año, especialmente en diciembre, para reunirse con sus familiares. Otros, dos veces al año, o cada tres meses. En algunos casos tienen hasta más de diez años de no ver a sus familiares por falta de recursos o porque no cuentan con pasaporte.

Tienen deseos de retornar a su país, pero una vez que haya más empleos y mejores salarios. Expresaron que si hubiera mejores oportunidades en Nicaragua, si regresarían. Además, extrañan a sus familiares y tienen deseos de estar con ellos. Otros añadieron que si contaran con el dinero se irían, con nostalgia mencionaron que "en Nicaragua hay donde construir, aqui a la orilla de 12 Un joven nicaragüense que murió en las garras de un par de perros rowuailer. 
un río". "Estoy agradecida pero no olvido mi país". "Amo a mi país". "Aquí no hay patios, en Nicaragua, si”. Ellos quieren tener animales, siente que no pueden tener ni perros. Para los nicaragüenses es muy importante tener animales domésticos, como compañía, seguridad, limpieza de otros tipos de animales, como alegría y adorno en el hogar, parte de los ingresos de la familia son destinados para la atención de estos animales, es por esa la razón de extrañarlos cuando van a vivir a otros lugares.

Se observa que los entrevistados, en su mayoría mujeres, se han dedicado sobre todo, a la atención de sus hijos, a trabajar, poca atención a su salud, a la distracción sana de todo ser humano, algunas se ven enfermas, con apariencia incluso de ser personas con mayor edad de la que tienen. Surgió en ellas cierto ánimo al realizarles la entrevista, observaban como si llegara alguien a ayudarles sobre todo para la comunicación con el gobierno de Nicaragua y busque la manera de ayudar a los migrantes nicaragüenses en Costa Rica, que por pura necesidad económica han tenido que partir de su país. Es una gente más joven con ánimo de trabajar, pero igual siempre se ve mucha pobreza y con problemas de salud. Le envían saludos al presidente, que si se arregla la situación regresarían.

\subsection{Nuevas culturas adquiridas.}

En Costa Rica entre 1995 y 2005 los niveles de enseñanza a los que más acuden los migrantes nicaragüenses son I y II Ciclo y Educación Diversificada; Preescolar; Escuela Nocturna y Educación Especial. Una característica es la extraedad por arrastre o por decisiones administrativas de no reconocer el último grado cursado en el país de origen. Hay lugares de atracción de migrantes temporales que significan nuevos alumnos en el transcurso de un año escolar y para ellos no se ha tomado en cuenta los materiales de estudio que estos demandan.

La matrícula inicial de extranjeros nicaragüenses en Costa Rica, entre 1995 y 2005, en todos los niveles de estudio fue ascendiendo de 9.991 en 1995 a 35.386 en el 2005. El 60\% de inmigrantes nicaragüenses en Costa Rica tienen entre 20 y 49 años y cerca del $70 \%$ con10 años y más no supera los 6 años de escolaridad; no priorizan la educación, puesto que lo principal para ellos es trabajar, están fuera del sistema educativo el 20\% de la población de 7 a 12 años y un $65 \%$ los que están entre las edades de 13 a 19 años. 8. Aspectos sociales y culturales que se desarrollan en el proceso migratorio. 
La diversidad cultural, la comida nicaragüense ha penetrado en los hogares costarricenses a través de las mujeres nicaragüenses que trabajan como domésticas. Se imponen valores culturales, se transmiten costumbres, pero también se adquieren ciertas costumbres en el comportamiento. La riqueza cultural de las personas, los niños costarricenses son educados por nicaragüenses, influyen en la comida, por otro lado los nicaragüenses adquieren costumbres de Costa Rica, aunque ellos no olvidan sus comidas típicas y por eso asisten al parque La Merced, en San José, donde se reúnen para recordar a su país.

Se ha creado la cultura de portar documentos, frente a los problemas de la población indocumentada. Se han desarrollado nuevas técnicas de trabajo en la construcción tanto en Estados Unidos como en Costa Rica. También nuevos conocimientos en el campo agrícola, en general los flujos migratorios han enriquecido la cultura. Se han combinado las comidas, donde inciden las nicaragüenses. En términos tecnológicos, los trabajadores de la construcción han mejorado sus técnicas, alcanzando una mejor calificación. Hay nuevas técnicas de siembra. Una mano de obra más preparada.

Los nicaragüenses que van Costa Rica dejan sus familias, lo hacen con muchos sacrificios, la migración de ellos es de hace muchos años, es especial, humilde, son personas trabajadoras, esforzadas, de rasgos atractivos. Cuentan leyendas que transmiten a los costarricenses. En los aspectos sociales culturales y sociales los nicaragüenses han aprendido a hacer filas, a no depositar la basura en cualquier lugar. Además disciplina, aseo, buenos hábitos. Por otro lado los costarricenses se han integrado a actividades como "La Purísima" el 8 de diciembre, lo mismo que han asimilado el sabor de la comida nicaragüense. Se celebra donde hay nicaragüenses como La Carpio, Alajuelita. Estas actividades no pasan desapercibidas. Están aprendiendo a comer "vigorón" a base de yuca y chicharrones, a partir de la labor doméstica de las mujeres nicaragüenses.

\section{CONCLUSIONES}

En esta investigación se cumplió con un máximo de acierto con los objetivos. El fin principal era identificar un problema económico-social, que tiene muchos años y que muy pocas soluciones se le ha brindado. Han formado parte del mismo muchas generaciones de nicaragüenses, hecho que evidencia una vez más que Nicaragua más que un país de inmigrantes, es un país de emigrantes, los estudios anteriores y el presente confirman que se desarrolla en el país una emigración neta. 
Se confirma en su proceso migratorio la teoría expulsión y atracción, las salidas son de todo el país, de las diferentes regiones, la atracción va a depender de las condiciones que tengan que ver con el aspirante a emigrar, entre otros aspectos la economía, la presencia de un familiar en el país de origen seleccionado, entre los cuales destacan los Estados Unidos de América y Costa Rica.

Es importante destacar que en cada uno de los países donde hay inmigrantes nicaragüenses reconocen su labor como trabajadores y los casos en los que se le vincula a desordenes son mínimos. Las situaciones de rechazo se dan sobre todo por una reacción al extranjero cuando no se le conoce, pero luego de tratar a los nicaragüenses identifican en ellos sus virtudes en el trabajo, su empeño por salir adelante, por calificarse y su expresión natural, aunque también muy decidido si alguien quiere afectar su espacio y sus derechos como seres humanos.

La migración para los países receptores en ocasiones la consideran un problema que resolver, pero también como una oportunidad que aprovechar, razón por la cual son mayores las ventajas que reciben al incrementar sus economías, que lo que invierten en la seguridad social de los inmigrantes. Y no solamente salen beneficiados los gobiernos, sino también el sector empresarial y las casas facilitadoras de las transacciones de las remesas.

Por otro lado el país de origen debe revisar su agenda de trabajo y no permitir que la migración se torne una facilidad para gobernar, puesto que no hay una mayor preocupación por el aprovechamiento de los recursos y la generación de empleos y desarrollar nuestras propias economías como en años anteriores, que si bien es cierto las circunstancias coyunturales en las últimas décadas no ha favorecido la economía, es el momento de iniciar y al menos superar los años setenta, dado que el crecimiento económico actual es similar al de 1978, según las informaciones del Banco Central de Nicaragua.

La investigación tiene un carácter "espaciotemporal", porque estudia el fenómeno de la migración en Nicaragua, atendiendo a la evolución de la misma, las causas que han inducido a los nicaragüenses a salir de su país, y la más sentida según el estudio es la razón económica, independientemente que hayan sucedido factores políticos, esta se ha conjugado, realmente el individuo social, no lo podemos separar de su vida económica y política, las causas se han mezclado y al final la que más prevalece es la económica, actualmente existe en Nicaragua el mayor desempleo que haya existido en la historia del país, el trabajo es por turno según el partido en el poder, los salarios no cubren todas las demandas básicas de las mayorías. Entonces la 
solución aparentemente fácil pero a la vez difícil es emigrar, aventurarse, exponerse, abandonar a los seres queridos con la esperanza de verlos algún día, como el sueño que se lleva de conquistar el mundo, y si encuentran trabajo, y envían dinero a sus familiares, pero la situación para todos no es igual.

Se observa en el estudio que hay diferencias en los migrantes, los que van a Costa Rica, tienen menos recursos que los que van a Estados Unidos, en ambos países pueden trabajar, pero igual pueden tener éxito o sufrir las trivialidades de ser un extraño de esa tierra en la cual vive.

En el estudio se vislumbran también consecuencias importantes, sobre todo la de sobrevivencia, pero igual es un ciudadano nicaragüense que independientemente se encuentre lejos de la patria, no significa que ya no existe y por eso el gobierno no se va a preocupar por ellos, es necesario al contrario que se mantengan las mejores relaciones con estos países que reciben a los que van a ganarse la vida y la de sus familias porque en su país no encuentra ese sustento y si lo tiene es limitado para obtener lo básico de una vida acorde a la dignidad humana.

En el trabajo constantemente se habla del papel de los medios de comunicación tanto en el país de origen como en los de destino, y quizá se hayan dedicado más al insumo comercial de vender la noticia y con ello se fomentan roces entre los ciudadanos de los países involucrados y es probable que las relaciones no sean tan ásperas, y se pueda tener una mejor armonía y que se permita a las personas la migración entre los países como una opción para vivir sin problemas en otro lugar y no que a la par que se va por necesidad tiene que enfrentarse a situaciones muy duras que incluso puedan atentar contra su integridad física, la separación casi absoluta de sus seres queridos y la pérdida de valores culturales del país.

En cuanto a las remesas vienen a solucionar un problema económico, destinadas especialmente al consumo, en un futuro es conveniente dado que seguirán existiendo que se optimicen en términos económicos, educativos, turísticos, en general un aprovechamiento para los y las migrantes, sus familiares y el país en general.

Aunque se debe tener presente que la situación económica de Nicaragua no se resuelve a través de las remesas familiares, su desarrollo no lo puede lograr exportando su capital humano que es un costo para el bienestar de todos y por otro lado las remesas tienen sus momentos de auge y declive. 
Se puede inferir a partir del presente trabajo que la definición de una nueva política migratoria en Costa Rica debe inducir a un cambio de visión de la sociedad costarricense hacia los migrantes, ser una sociedad más abierta y aceptar la diversidad que en el fondo no es muy diferente puesto Nicaragua y Costa Rica son países con culturas similares, de una misma región.

Es conveniente la regularización de la migración para favorecer la inclusión, crear de manera conjunta ambos países las correspondientes entidades gubernamentales relacionadas con la migración, lo mismo que facilitar información a los migrantes. Hace falta un balance de la pérdida de la fuerza laboral y recursos humanos, una estrategia de desarrollo incluyente, espacios de trabajo con participación de gobierno, organizaciones y organismos internacionales, estimular la migración en condiciones de regularidad y que se ejecuten los derechos humanos de los migrantes. El tema de las migraciones debe incidir en las políticas públicas.

\section{FUENTES Y BIBLOGRAFÍA}

Abu, S: (1989). Los aportes culturales de los inmigrados. Metodología y conceptualización. En Le Ander, B.: Europa, Asia y África en América Latina y el Caribe. México, UNESCO/siglo XXI.

Audera, V: (1954). La población y la inmigración en Hispanoamérica. Ed. Cultura Hispánica.

Cavallaro, Renato: (1985). La memoria biográfica. Significado y técnicas en la dinámica de los procesos migratorios. En Estudios migratorios latinoamericanos. N. 1. Dic. Buenos Aires, CEMLA.

Contreras, J. (Comp.) Los retos de la inmigración.

Castilla R. Rodolfo. Balance y Perspectiva de las Migraciones Forzadas de Centroamérica. Departamento de Asuntos Jurídicos Internacionales. Oficina de Cooperación Jurídica.

Cortés Ramos, A: Reflexiones sobre la Dinámica migratoria Nica-Tica

Coordinación Educativa y Cultural Centroamericana: (2000) Historia del Istmo Centroamericano. San José, Costa Rica. 
Devoto, F. Revista de Estudios Migratorios en América Latina.

Devoto, F: (1992). Movimientos migratorios: historiografia y problemas., Buenos Aires, Centro Editor de América Latina

García M, E: Las migraciones forzadas en Centroamérica

Herrera Cuaresma Miguel Angel. Migraciones Nicaragüenses, un enfoque histórico. Nicaragua UCA. Nicaragua.

Oficina Internacional. Las migraciones internacionales; 1945-1957

SánchezAlbornoz, N:(1977). Lapoblación de América Latina desde los tiempos procolombinos al año 2025. Madrid. Alianza Editorial.

Tellería Geiger, José L: (2000). Integración Latinoamericana. Una desazón colectiva. Bolivia.

Torres, Olimpia: Las migraciones de Nicaragua al exterior. Un análisis de perspectiva. 


\title{
ANEXOS
}

\author{
Cuadro 1.
}

NICARAGUA: INDICADORES MACROECONÓMICOS 1980 - 1990

\begin{tabular}{|l|l|l|l|l|l|}
\hline INDICADOR/AÑOS & 1980 & 1983 & 1985 & 1987 & 1990 \\
\hline Export. (US \$ mill.) & 514 & 478 & 340 & 324 & 384 \\
\hline Inflación (\%) & 24,8 & 32,9 & 334,3 & $1.347,2$ & 13.490 \\
\hline Deuda externa (US \$ mill.) & 1.571 & 3.263 & 4.618 & 6.262 & 8.064 \\
\hline Crecimiento PIB (\%) & 4,5 & 4,6 & $-4,1$ & $-0,7$ & $-4,4$ \\
\hline PIB percápita (US \$) & 750,6 & 743,6 & 656,1 & 602,7 & 430,6 \\
\hline
\end{tabular}

Fuente; Secretaría de Planificación y Presupuesto (SPP) Managua, Nicaragua, 1989.

\section{Cuadro 2.}

Costa Rica y Nicaragua: salarios medios por hora (en dólares), 1998.

\begin{tabular}{|l|l|l|l|l|l|}
\hline Países/Actividades & $\begin{array}{l}\text { P e ó n } \\
\text { agrícola }\end{array}$ & Albañil & Comercio & Maestras & Enfermeras \\
\hline Costa Rica & 1,63 & 1,34 & 1,06 & 3,05 & 5,99 \\
\hline Nicaragua & 0,37 & 0,68 & 0,61 & 0,45 & 0,62 \\
\hline
\end{tabular}

Fuente: Elaboración a partir de: Baumeister (2001): Nicaragua. Migraciones Externas, Cuadernos del CONPES. Pág.16; en base a Miguel de Cid y Rodolfo Tacsan Chen (1998) ${ }^{13}$ 


\section{Cuadro 3.}

Nicaragua Población Emigrante. Distribución relativa según nivel educativo por sexo y principales países de destino. 2004

\begin{tabular}{|l|l|l|l|l|}
\hline Nivel Educativo y Sexo & Total & Centroamérica & Costa Rica & $\begin{array}{l}\text { Resto del } \\
\text { mundo }\end{array}$ \\
\hline Total (100\%) & 214.723 & 119.071 & 97.543 & 183.472 \\
Sin ningún nivel / Primaria & 20,0 & 29,8 & 30,6 & 8,2 \\
incompleta & & 20,3 & 19,4 & 12,1 \\
Primaria completa & 16,6 & 27,5 & 27,7 & 22,2 \\
Secundaria incompleta & 24,9 & 16,1 & 16,4 & 29,3 \\
Secundaria completa & 21,9 & 1,4 & 1,3 & 3,5 \\
Técnico medio & 2,4 & 4,8 & 4,6 & 24,7 \\
Universidad & 14,1 & 60.931 & 50.450 & 89.437 \\
\hline Hombres (100\%) & 107.494 & 32,9 & 34,4 & 8,2 \\
Sin ningún nivel / Primaria & 22,2 & & & \\
incompleta & & 20,0 & 18,9 & 11,7 \\
Primaria completa & 16,4 & 26,7 & 27,0 & 25,7 \\
Secundaria incompleta & 25,9 & 14,8 & 14,7 & 27,2 \\
Secundaria completa & 20,0 & 0,5 & 0,2 & 2,2 \\
Técnico medio & 1,4 & 5,1 & 4,7 & 25,0 \\
Universidad & 14,3 & &
\end{tabular}




\begin{tabular}{|l|l|l|l|l|}
\hline Mujeres (100\%) & 107.230 & 58.140 & 47.093 & 94.035 \\
Sin ningún nivel / Primaria & 18,0 & 26,5 & 26,5 & 8,2 \\
incompleta & & 20,7 & 19,9 & 12,6 \\
Primaria completa & 16,8 & 28,3 & 28,4 & 18,9 \\
Secundaria incompleta & 24,0 & 17,5 & 18,2 & 31,2 \\
Secundaria completa & 23,7 & 2,4 & 2,5 & 4,7 \\
Técnico medio & 3,5 & & & \\
Universidad & & & & \\
\hline
\end{tabular}

Fuente: Proyecto SIEMMES-OIM con base en información del Instituto Nacional de Estadística y Censos de Nicaragua. Encuesta Nacional para la Medición de Empleo Urbano- Rural. 2004.

\section{Cuadro 4.}

HOGARES ENCUESTADOS QUE RECIBEN REMESAS DEL EXTERIOR (\%)

\begin{tabular}{llll}
\hline Tipos de Remesas & Área Urbana & Área Rural & Total Nacional \\
\hline En dinero & 49 & 55 & 50,0 \\
En bienes o regalos & 22 & 20 & 21,5 \\
Ambos & 29 & 25 & 28,5 \\
Totales & 78 & 22 & 100,0 \\
\hline Remesas en dinero $*$ & 20 & 7 & 14,3 \\
\hline
\end{tabular}

* Incluye hogares que reciben sólo dinero y los que reciben ambos tipos de remesas. Los porcentajes se refieren al total de hogares encuestados en cada área de residencia.

Fuente: EMNV 2001 


\section{Cuadro 5.}

Matrícula inicial de nicaragüenses en Costa Rica según nivel de enseñanza. 1995 y 2005

\begin{tabular}{|l|l|l|l|}
\hline Nivel & 1995 & 2005 & Incremento \% \\
\hline Preescolar & 430 & 1.933 & 349,5 \\
\hline I y II Ciclo & 7.981 & 24.316 & 204,7 \\
\hline Escuelas Nocturnas & 84 & 153 & 82,0 \\
\hline $\begin{array}{l}\text { III Ciclo y Educación } \\
\text { Diversificada }\end{array}$ & 1.441 & 8.590 & 496,0 \\
\hline Educación Especial & 55 & 394 & 616,4 \\
\hline Total & 9.991 & 35.386 & 254,0 \\
\hline
\end{tabular}

Fuente: Elaboración personal con estadísticas del MEP, Costa Rica. ${ }^{14}$

14 Carmona Segnini Ana Cristina. Diagnóstico de la capacidad institucional educativa actual y sus principales desafíos. En Migración y Políticas Públicas para el desarrollo. Costa Rica, 2007. pág.90 